\title{
Cytotoxic Chemotherapy and CD4+ Effector T Cells: An Emerging Alliance for Durable Antitumor Effects
}

\author{
Zhi-Chun Ding ${ }^{1}$ and Gang Zhou ${ }^{1,2}$ \\ ${ }^{1}$ Cancer Immunotherapy Program, Cancer Center, Georgia Health Sciences University, Augusta, GA 30912, USA \\ ${ }^{2}$ Hematology/Oncology Section, Department of Medicine, School of Medicine, Georgia Health Sciences University, \\ Augusta, GA, USA \\ Correspondence should be addressed to Gang Zhou, gzhou@georgiahealth.edu
}

Received 12 July 2011; Revised 1 November 2011; Accepted 5 November 2011

Academic Editor: Takami Sato

Copyright (๑) 2012 Z.-C. Ding and G. Zhou. This is an open access article distributed under the Creative Commons Attribution License, which permits unrestricted use, distribution, and reproduction in any medium, provided the original work is properly cited.

Standard cytotoxic chemotherapy can initially achieve high response rates, but relapses often occur in patients and represent a severe clinical problem. As increasing numbers of chemotherapeutic agents are found to have immunostimulatory effects, there is a growing interest to combine chemotherapy and immunotherapy for synergistic antitumor effects and improved clinical benefits. Findings from recent studies suggest that highly activated, polyfunctional CD4+ effector T cells have tremendous potential in strengthening and sustaining the overall host antitumor immunity in the postchemotherapy window. This review focuses on the latest progresses regarding the impact of chemotherapy on CD4+ T-cell phenotype and function and discusses the prospect of exploiting CD4+ T cells to control tumor progression and prevent relapse after chemotherapy.

\section{Introduction}

As a major treatment modality for many advanced cancers, conventional chemotherapy can achieve high response rates but is rarely curative. The mounting evidence that many chemotherapeutic agents have immunostimulatory effects has provided a compelling rationale for developing combined chemoimmunotherapy strategy to achieve improved patient outcomes [1-3]. Current cancer immunotherapies predominantly rely on CD8+ T cells to fight against tumors. Although it is increasingly clear that proinflammatory CD4+ effector $\mathrm{T}$ cells are critical determinants of effective antitumor immune responses [4-9], the utilization of CD4+ T cell-based immunotherapy in combination with chemotherapy to control tumor progression and recurrence has not been fully explored. Nonetheless, a plethora of information accumulated from preclinical and clinical studies suggests that these two treatment modalities might be mutually reinforcing, and therefore their combination represents an effective chemoimmunotherapy strategy.

\section{Anticancer Drugs and Immune Activation}

Anticancer drugs are selected for their cytotoxicity toward cancerous cells. Although some anticancer drugs were known to have immune-potentiating effects long time ago $[10,11]$, the therapeutic potential of this property has been largely ignored. As increasing numbers of conventional chemotherapeutic agents are found to possess immunostimulatory properties, it has come to the realization in recent years that elicitation of the host antitumor immunity may constitute an integral component of the anticancer efficacy of some antineoplastic agents [12].

Multiple classes of anticancer chemotherapeutic drugs have been reported to exert immune enhancing effects, and a number of them have been extensively studied. Cyclophosphamide (CTX) is an alkylating agent chemically related to nitrogen mustard. As a prodrug, CTX is converted into its active metabolite derivative phosphoramide mustard in the liver. Phosphoramide mustard inhibits DNA replication by forming crosslinks between (interstrand) and 
within (intrastrand) DNA strands. CTX is often used in combination with other anticancer drugs in the treatment of lymphomas and some solid tumors. Doxorubicin is a cytotoxic anthracycline antibiotic. It is known to bind to nucleic acids by intercalating the DNA strands and disrupting DNA replication. Doxorubicin is commonly used to treat hematological malignancies (leukemia, lymphoma, and multiple myeloma), and many types of solid tumors. Gemcitabine is a pyrimidine nucleoside analog that acts as an antimetabolite. Gemcitabine is used in a wide range of carcinomas, including lung, pancreatic, breast, and bladder cancer. Paclitaxel and docetaxel belong to the taxane class of drugs that act as mitotic inhibitors. These drugs cause cell-cycle arrest by stabilizing GDP-bound tubulin in microtubules, thereby disrupting the process of cell division. They are currently used to treat patients with lung, breast, prostate, and ovarian cancer. Cisplatin and oxaliplatin are platinumbased anticancer drugs. These platinum complexes induce apoptosis in malignant cells by causing crosslinking of DNA.

Although these anticancer drugs cause tumor destruction through different mechanisms, they share some common features in exerting immune-enhancing effects.

2.1. Inducing Immunogenic Tumor Cell Death. Tumor cells killed by anticancer drugs not only provide the source of tumor antigens but also release "danger signals" that awaken the innate immune cells, which in turn activate the adaptive immune system. Studies from Zitvogel's group have characterized several prominent features of immunogenic cell death after cytotoxic chemotherapy, including translocation of calreticulin (CRT), secretion of high-mobility-group box 1 (HMGB1), and release of adenosine triphosphate (ATP) by dying tumor cells. These studies reported that doxorubicin induces rapid translocation of the endoplasmic reticulumresident protein calreticulin to tumor-cell surface, presenting a "eat-me" signal for phagocytosis by dendritic cells [13]. HMGB1 released by dying tumor cells after doxorubicin or oxaliplatin treatment acts upon toll-like receptor 4 (TLR4) on dendritic cells to initiate efficient antigen processing and presentation that involves the Myd88-signaling pathway [14]. Doxorubicin and oxaliplatin can also induce release of ATP by tumor cells, which triggers purinergic $\mathrm{P} 2 \mathrm{RX} 7$ receptors on dendritic cells (DCs) to activate the NOD-like receptor family, pyrin-domain-containing protein 3-dependent caspase1 activation complex, namely, the NLRP3 inflammasome, which ultimately leads to IL- $1 \beta$-dependent adaptive immunity [15]. Along the same line, cyclophosphamide has been recently reported to cause CRT translocation and HMGB1 release in some types of tumor [16, 17]. Furthermore, it has been shown that tumor-cell apoptosis induced by gemcitabine can enhance DC cross-presentation of tumor antigen to CD8+ T cells [18], but it is not yet clear whether CRT translocation, mobilization of HMGB1, and ATP are involved in the process.

2.2. Mitigating Immunosuppressive Mechanisms. The ability of tumors to evade immune destruction is critical for tumor formation and progression and is now regarded as an emerging hallmark of cancer [19]. Under the selection pressure imposed by natural immune surveillance or therapeutic interventions, tumors may avoid immune attacks through passive mechanisms such as downmodulating the expressions of the relevant MHC-I molecules and antigens [20, 21]. In addition, tumor cells have evolved to employ multiple immune regulatory mechanisms to actively attenuate and subvert antitumor immune responses. Regulatory $\mathrm{T}$ cells (Treg) and myeloid-derived suppressor cells (MDSCs) are frequently enriched in the tumor microenvironment and facilitate tumor immune evasion [22]. Some chemotherapeutic agents can potentiate antitumor immune responses by directly targeting these immunosuppressive cells. Lowdose cyclophosphamide $(100 \mathrm{mg} / \mathrm{kg})$ is capable of depleting cycling CD4+CD25+ Tregs and inhibiting their suppressive activity $[23,24]$. As a result, the effector activities of cytotoxic $\mathrm{CD} 8+\mathrm{T}$ cells and NK cells are unmasked to control tumor growth [25-27]. A recent study has suggested that CTX can preferentially deplete tolerogenic CD8+ lymphoid-resident DCs, leading to diminished Treg suppression and enhanced effector T-cell function as manifested by induction of concomitant immunity in a prophylactic setting [28]. It is currently unclear whether this mechanism of action is operative in a therapeutic setting. On a different note, gemcitabine does not deplete Tregs [24] but selectively reduces $\mathrm{CD} 11 \mathrm{~b}+\mathrm{Gr} 1+$ MDSCs and enhances the antitumor activities of CD8+ T cells and NK cells [29].

2.3. Creating Lymphopenia and Immunogenic Milieu. Many anticancer drugs can cause varied degree of lymphodepletion [30]. It has been well established that lymphodepletion induced by chemotherapy or radiotherapy profoundly enhances the efficacy of adoptive cell therapy (ACT) and cancer vaccines [31]. This is likely due to the combined effects of creation of space and increased availability of stimulatory growth factors that lead to enhanced proliferation and survival of activated $\mathrm{T}$ cells [32]. In this regard, cyclophosphamide is a representative anticancer drug that causes profound lymphodepletion while creating an immune milieu rich of type I interferons (IFNs) and common gamma-chain cytokines (IL2, IL7, and IL15) [33, 34]. Of notice, type I interferons are known to promote DC maturation and T-cell differentiation [35-38]. IL7 is essential for survival and memory formation of tumor-reactive $\mathrm{T}$ cells, and neutralization of IL7 after CTX administration diminishes the number of tumor-reactive $\mathrm{T}$ cells in an adoptive transfer model [33]. Besides strengthening the activities of immune cells, chemotherapy also promotes the trafficking of activated immune cells to the sites of tumor $[33,39,40]$. Accumulating evidence demonstrates that there is a surge of proinflammatory cytokines/chemokines, such as GMCSF, IL1 $\beta$, IL6, and CXCL10, in the postchemotherapy immune milieu, which may contribute to the recruitment and retention of tumor-reactive immune cells, including activated CD8+ and CD4+ T cells, DCs, macrophages, and neutrophiles, in the tumor microenvironment $[15,17,34]$. 
2.4. Sensitizing Tumor Cells to Immune Destruction. In addition to attracting activated immune cells to the tumor loci, chemotherapy may render tumor cells more susceptible to immune attack. It has been shown that doxorubicin, cisplatin, and paclitaxel can sensitize tumor cells to the cytolytic effect of CD8+ T cells by making them permeable to granzyme B via mannose-6-phosphate receptors on the surface of tumor cells [40]. Moreover, chemotherapy with cyclophosphamide can sensitize tumor cells to TRAILdependent CD8+ T cell-mediated immune destruction [41].

\section{Chemotherapy and Antitumor CD4 Responses}

A great deal of effort has been focused on understanding how chemotherapy potentiates CD8+ T-cell responses [27, 38, 41, 42], mitigates Treg-mediated immune suppression [23, 26, 43], and enhances antigen presentation [13, 14, 28, 44, 45]. Although tumor-reactive CD4+ effector/helper T cells are increasingly recognized as critical determinants of effective antitumor immune responses, the effect of chemotherapy on these cells is largely neglected, and the role of CD4+ $\mathrm{T}$ cells in modulating postchemotherapy host immunity is almost entirely unknown. In the following we mainly focus on findings that concern the impact of chemotherapy on the interactions between tumors and CD4+ T cells.

3.1. CD4+ $T$ Cells Subsets and Their Diverse Roles in Tumor Immunity. Upon stimulation naïve CD4+ T cells differentiate into effector cells known as T helper (Th) cells. Originally Th cells were classified into Th1 and Th2 lineages, depending on the cytokine profiles of the effector cells [46]. With the discovery of new T-cell lineages in recent years, the Th1/Th2 paradigm has been revised to reflect a much broadened spectrum of CD4+ T-cell subsets. It has now been established that naïve CD4+ $\mathrm{T}$ cells can differentiate into four major lineages, including Th1, Th2, Th17, and Treg cells [47], and that Th cells are plastic-cells of one lineage can be converted to another lineage under certain circumstances [48].

The distinct CD4+ T-cell subsets have varied impact on tumor growth. Th1 cells, characterized by production of IFN $\gamma$ and TNF $\alpha$, often lead to enhanced activation of cytotoxic CD8+ T cells, DCs and macrophages, exhibiting beneficial antitumor effects. In contrast, IL4-producing Th2 cells may promote tumor progression by enhancing the activity of protumor macrophages [49] although Th2 cells can also mediate tumor rejection under certain condition [50]. Currently there is much debate about the role of Th17 cells in antitumor immunity [51], because both tumor rejection and tumor promotion involving Th17 cells and their major product proinflammatory cytokine IL17 have been reported [52-55]. Treg cells act to dampen antitumor immunity by suppressing the effector functions of a variety of immune cells, including Th1 cells [56-58], CD8+ T cells [5], NK cells [59], and tumor-infiltrating DCs [60].
3.2. Effect of Chemotherapy on CD4+ T-Cell Effector Development. So far, among the aforementioned anticancer drugs, cyclophosphamide (CTX) appears to be the most effective one in enhancing antitumor CD4 responses, particularly when used in combination with adoptive cell therapy (ACT). It has been demonstrated in various preclinical models that CTX treatment followed by adoptive transfer of tumorreactive $\mathrm{CD} 4+\mathrm{T}$ cells, either monoclonal $\mathrm{T}$-cell clones derived from TCR-transgenic mice, or activated polyclonal $\mathrm{CD} 4+\mathrm{T}$ cells derived from preimmunized mice, leads to eradication of established tumors [61-64]. One salient observation from these studies is that the robust antitumor effects are associated with the development of Th1 antitumor immunity. In line with an early study showing that CTX induced a Th2 to Th1 shift in the cytokine profile of lymphoma-bearing rats [65], we have recently reported in a mouse lymphoma model that CTX overcomes tumor-driven aberrant CD4+ T-cell differentiation and directs CD4+ T cells to become highly activated polyfunctional effector cells, marked by their ability to concomitantly produce multiple Th1-type cytokines including IL2, IFN $\gamma$, and TNF $\alpha$ [64]. In a mouse melanoma model, Quezada et al. reported that tumor-specific CD4+ T cells acquired a similar polyfunctional phenotype in postradiotherapy hosts [66], suggesting that the immunogenic milieu created by chemotherapy or radiotherapy may share some common features in terms of driving CD4+ T-cell effector differentiation. In addition to promoting Th1 differentiation, there is emerging evidence that CTX also induces Th17 cells [34, 67]. These Th17 cells are likely de novo induced in the postchemotherapy milieu, because they are not converted from Treg cells [67], and do not coexpress IFN $\gamma$ [34]. In contrast, doxorubicin and oxaliplatin each induces IL17-producing $\gamma \delta \mathrm{T}$ cells but not Th17 cells [68]. It will be of interest to test additional anticancer drugs to define the common features of the drugs that are capable of driving effector CD4 responses like CTX.

\subsection{Mechanisms by Which Anticancer Drugs Modulate CD4} Responses. Even though CTX is by far the most potent CD4potentiating anticancer drug demonstrated experimentally, the cellular and molecular mechanisms underlying its effect are not well understood. In addition to its well-known effect of depleting suppressor $\mathrm{T}$ cells, accumulating evidence has established a link between productive $\mathrm{CD} 4+\mathrm{T}$-cell responses and an immunogenic milieu induced by CTX [17, 33, 36, 64]. The immunogenic milieu is rich of various growth factors and proinflammatory cytokines and chemokines, among which type I IFNs and IL7 have been shown to exert particularly important immunostimulatory effects. Type I IFNs can augment immune responses through enhanced stimulation of dendritic cells [69]. It has been shown that DCs require type I IFNs to mature and induce CD4+ Th1 immunity [70]. In the same vein, a recent study has reported that IFN $\alpha$ enhances $\mathrm{T}$ helper cell functions while reducing Treg activity through modulating APC activation [71]. In addition to supporting T-cell survival and homeostasis, IL7 has recently been shown to antagonize cbl-b and TGF $\beta$ signaling, two pathways involved in inhibiting T-cell activation, leading to 
augmented Th17 differentiation [72]. Moreover, it has been reported that IL7 promotes Th1-like immunity and inhibits Treg activity $[73,74]$. Altogether it is conceivable that CTX's multifaceted and dynamic immunomodulatory effects, for example, depletion of Treg, creation of lymphopenia, and induction of stimulatory cytokines superimpose to foster a profoundly immunogenic milieu that drives the development of fully differentiated Th1 or Th17 effector T cells. To better understand the mechanisms underlying the diverse CD4+ T-cell differentiation in postchemotherapy setting, future studies should dissect the interrelation of the abovementioned contributing factors, and their relative contribution to the functional development of tumor-specific CD4+ T cells.

\subsection{Antitumor Effects of CD4+ Effector T Cells}

3.4.1. Activating Tumoricidal CD8 and Macrophages and Sensitizing Tumor Stroma. CD4+ T cells have been regarded as specialized helper cells that assist in the activation of other innate and adaptive immune cells. Once properly activated, CD4+ T cells express an array of effector molecules, including CD40L, IL2, IFN $\gamma$, and TNF $\alpha$, which play critical roles in orchestrating effective antitumor immune responses. Consistent with the well-defined role of CD40L in transmitting CD4 help for CD8+ T cells [75-77], it has been shown in different animal models that activated CD4+ T cells can license DCs in the tumor microenvironment via CD40L-CD40 interaction, leading to priming of tumor-reactive CD8+ T cells which in turn mediate long-term protection $[78,79]$. In addition to licensing of DC, some previously unappreciated help activities of CD4+ $\mathrm{T}$ cells have recently been uncovered, revealing the molecular basis of the once vaguely-defined "post-licensing" role of CD4+ T cells [80]. For example, it has been shown that CD4+ effector $\mathrm{T}$ cells recruit activated $\mathrm{CD} 8+\mathrm{T}$ cells via the action of IFN $\gamma[81,82]$ and promote CD8+ T-cell cytolytic function and proliferation through IL2 [82]. Besides targeting tumor cells, CD4+ effector T cells have been implicated in inhibiting tumor angiogenesis by acting on tumor stroma via IFN $\gamma$ [83]. Given that CD8+ $\mathrm{T}$ cell-derived TNF $\alpha$ and IFN $\gamma$ can sensitize tumor stroma and mediate bystander tumor eradication [84], we speculate that polyfunctional CD4+ effector $\mathrm{T}$ cells have the same effect because these cells can produce these two cytokines simultaneously [34]. Notably, it has been reported that Th1derived IFN $\gamma$ also renders macrophages cytotoxic to cancer cells $[6,85]$. Interestingly, Beatty et al. reported that CD40activated macrophages become tumoricidal and facilitate the destruction of tumor stroma in mice and humans with pancreatic carcinoma [86]. Although this study used an agonist CD40 antibody to activate macrophages, it is tempting to speculate that CD40L-expressing CD4+ effector $\mathrm{T}$ cells would achieve similar effects.

3.4.2. Conditioning a Protective Inflammatory Milieu. Chemotherapy often induces inflammation in the tumor microenvironment by causing tumor cell death and tissue damage. Paradoxically, many of the proinflammatory cytokines induced after chemotherapy, particularly IL1 $\beta$, IL6, and IFN $\alpha / \beta$, can exert both tumor-inhibiting and tumor-promoting effects (double-edged sword) $[87,88]$. On one hand, IFN $\alpha / \beta$ and IL1 $\beta$ both can directly act on CD $4+\mathrm{T}$ cells to enhance their activation and differentiation [89-92]. In addition, IFN $\alpha / \beta$ and IL1 $\beta$ can augment antigen presentation and facilitate priming of T cells $[15,37,70,93]$. Moreover, IL6 and IFN $\alpha / \beta$ can potentiate effector cells to resist Tregmediated suppression $[71,94]$, and IL6 and IL $1 \beta$ can mediate Treg $\rightarrow$ Th17 conversion [95-97]. On the other hand, IL1 $\beta$ and IL6 have been shown to drive tumorigenesis [98103] and dampen host immunity by expanding myeloidderived suppressor cells (MDSCs) [104-106]. IFN $\alpha / \beta$ are potent inducers of coinhibitory molecules PDL1 [107] and PD1 [108], and immunosuppressive enzyme indoleamine 2,3-dioxygenase (IDO) [109, 110]. Furthermore, it has been shown that IL6 contributes to chemoresistance [111]. Intriguingly, the efficacy of many cancer therapies is often associated with certain degree of inflammatory responses $[34,112,113]$. A recent study by Haabeth et al. has suggested that unopposed inflammation may promote tumor progression while the presence of Th1 cells can tilt inflammation toward effective antitumor immunity [85]. This hypothesis is supported by the observation that chronic inflammation associated with psoriasis, a Th1-mediated autoimmune disease affecting the skin, does not promote the development of skin cancers [114]. Therefore, it is likely that Th1 CD4+ $\mathrm{T}$ cells play a critical role in conditioning a tumor-inhibiting inflammatory milieu that facilitates immune activation and tumor destruction.

3.4.3. Mediating Direct Tumor Destruction. Besides rendering other immune cells tumoricidal, CD4+ T cells have the capability to mediate direct tumor destruction. It has been shown that CD4+ T cells can induce apoptosis in tumor cells through FAS- or TRAIL-dependent pathway $[115,116]$. Moreover, there is accumulating evidence that CD4+ T cells can acquire cytolytic activities like cytotoxic CD8 $+\mathrm{T}$ cells [117-121]. However, the significance of this property has been largely ignored, until recently two studies have provided compelling evidence that cytotoxic CD4+ T cells developed in a lymphopenic environment can eradicate established melanoma as a result of direct killing of the tumor cells through granzyme B $[66,122]$. Currently it is unknown whether cytotoxic CD4+ T cells and helper CD4+ T cells develop in parallel, or they are the same cells at different stages of differentiation. Nevertheless, Qui et al. provided evidence that costimulation through CD134 (OX40) and CD137 (4-1BB) is required to drive the differentiation of cytotoxic CD4+ effector cells in an eomesodermindependent manner [123]. Although cytotoxic CD4+ and CD8+ T cells appear to mediate tumor killing using the same effector molecules, such as granzyme B and perforin, they target MHC-II and MHC-I-restricted antigens, respectively. One important implication of CD4+ T-cell cytotoxicity is that CD4+ T-cell-mediated tumor destruction may result in antigen spreading, which is associated with broadened antitumor CD8 responses and improved clinical responses $[8,124-126]$. 
In summary, with an arsenal of diverse cancer-fighting weapons, CD4+ T cells can mediate tumor destruction either on their own or by cooperating with other immune cells. Whereas CD4+ $\mathrm{T}$ cells alone clearly have the potential to effectively eradicate tumors $[66,122,127]$, the majority of published studies indicate that the optimal antitumor effects are achieved when CD4+ T cells act in concert with tumorreactive CD8+ $\mathrm{T}$ cells $[8,78-80,128-133]$, macrophages [6], or NK cells [7]. A long-held perception is that CD4 antitumor immunity is only relevant to the treatment of MHC- $\mathrm{II}^{+}$tumors. Nevertheless, due to the wide-range mode of actions, CD4+ T cells have been shown to play active and indispensable roles in controlling both $\mathrm{MHC}-\mathrm{II}^{+}[63,64]$ and MHC-II ${ }^{-}$tumors $[6,7,78,79,127,134,135]$. It is worth noting that some solid tumors, melanoma, for instance, can be induced to express MHC-II upon encountering IFN $\gamma$ and thus become direct targets of CD4+ effector T cells $[66,122]$. Therefore, the generation of effective CD4+ T-cell responses has great therapeutic potential and broad clinical relevance.

\section{Inhibitory Mechanisms That Attenuate Antitumor CD4+ T-Cell Responses}

Tumor-specific CD4+ T cells are subject to a variety of tolerizing mechanisms operative in the tumor microenvironment. Induction of anergy in antigen-specific CD4+ T cells is an early event in the course of tumor progression [136]. We and others show that tumor-antigen recognition is accompanied with induction of both CD4+ effector cells and Tregs [56, 57, 137]. However, the tolerogenic nature of the tumor milieu progressively renders CD4+ effector T cells dysfunctional, characterized by sustained expression of PD1 and heightened apoptosis [64]. Thus, the anergic phenotype of the overall CD4 population represents the net result of Treg induction, effector dysfunction, and active immune suppression. Treg cells enriched in tumor may come from expansion of preexisting Tregs, and de novo induction of Treg cells [137, 138], which may occur in both antigen-dependent [138] and -independent [139] manner in tumor-bearing hosts. Pertaining to combinatory chemoimmunotherapy, it will be important to determine if highly activated CD4+ effector $\mathrm{T}$ cells are susceptible to Treg conversion in the face of minimal residual disease after chemotherapy. Although it has been shown that polarized Th1 effector cells and memory CD4+ T cells are refractory to conversion to Tregs [140, 141], whether this is the case in the postchemotherapy setting is yet to be addressed.

Tregs have been shown to attenuate antitumor responses through a variety of mechanisms, including deactivating DCs [142, 143], preventing CD8+ T-cell-mediated cytolysis [144], and direct killing of DC, NK, and CD8+ T cells $[145,146]$. Importantly, Tregs may operate in concert with other regulatory mechanisms, including MDSC, coinhibitory molecule PD1, and immunosuppressive enzyme IDO, to form a selfreinforcing immunosuppressive network, posing a severe threat to the magnitude and durability of an effective antitumor immune response. MDSCs can act as tolerogenic APCs to expand Tregs $[147,148]$. IDO+ DCs can directly activate Tregs which subsequently mediate suppression in a PD1/PDL1-dependent fashion [149]. Programmed death 1 (PD1) was initially found to mediate CD8+ T-cell functional exhaustion during chronic viral infections [150]. Subsequent studies confirmed the existence of exhausted PD1 ${ }^{\text {high }}$ CD8+ $\mathrm{T}$ cells during tumor progression $[151,152]$. However, the role of PD1 in regulating CD4+ T-cell response in the tumor context is less clear. Using a mouse B-cell lymphoma model, we provided clear evidence that PD $1^{\text {high }} \mathrm{CD} 4+\mathrm{T}$ cells constituted a fraction of tumor antigen-experienced cells and were associated with downregulation of IL7 receptor and elevated level of apoptosis [64]. Interestingly, we showed in this model that PD1 was not required for tumor-driven Treg induction, while two other studies reported that PDL1 was involved in peripheral Treg induction and maintenance $[153,154]$. Given that PD1 is not the only receptor for PDL1 [155-157], the seemingly discrepant results suggest that PDL1 on DCs may differentially regulate Treg induction and effector T-cell dysfunction through engaging different receptors on CD4+ $\mathrm{T}$ cells. This is supported by the observation that PD1 and Foxp3 have a nonoverlapping expression pattern in CD4+ $\mathrm{T}$ cells infiltrating B-cell lymphoma $[158,159]$. Collectively, these findings and the results from other studies [160-163] support a scenario in which Treg-mediated suppression and PD1-dependent T-cell dysfunction contribute independently but synergistically to the failed immunological control of tumor growth.

\section{Implications for Combined Chemoimmunotherapy}

Standard chemotherapy is a major treatment option for many types of cancer. It can effectively treat the symptom of cancer initially, but frequently its efficacy is compromised by late tumor recurrence. The ability of some anticancer drugs to drive productive $\mathrm{CD} 4+\mathrm{T}$-cell responses, and the versatile and pivotal roles of $\mathrm{CD} 4+$ effector $\mathrm{T}$ cells in mediating antitumor effects, provide strong rationales for developing a strategy that utilizes CD4+ effector T cells to strengthen and sustain the postchemotherapy antitumor immunity. This can be achieved clinically through the combination of chemotherapy and adoptive immunotherapy or therapeutic vaccination. Indeed, the efficacy of this strategy has been hinted by some elegant clinical studies, which showed that better immunological and clinical responses were obtained in melanoma or myeloma patients that had received CD4+ $\mathrm{T}$ cell-containing donor cells following preconditioning chemotherapy $[129,131]$.

To overcome tumor-induced immune tolerance, additional maintenance regimens are needed to keep CD4+ $\mathrm{T}$ cells in the polyfunctional effector state. Many of the currently available immune modulators [164], such as recombinant IL7, CD40 agonist, PD1 blockade, and CTLA4 blockade, can be applied to potentiate and sustain CD4 effectors in addition to enhancing antitumor CD8 responses. We showed that polyfunctional CD4+ T cells have the unusual distinguishing attribute of high levels of IL7 receptor expression [64], suggesting that these cells can be preferentially 


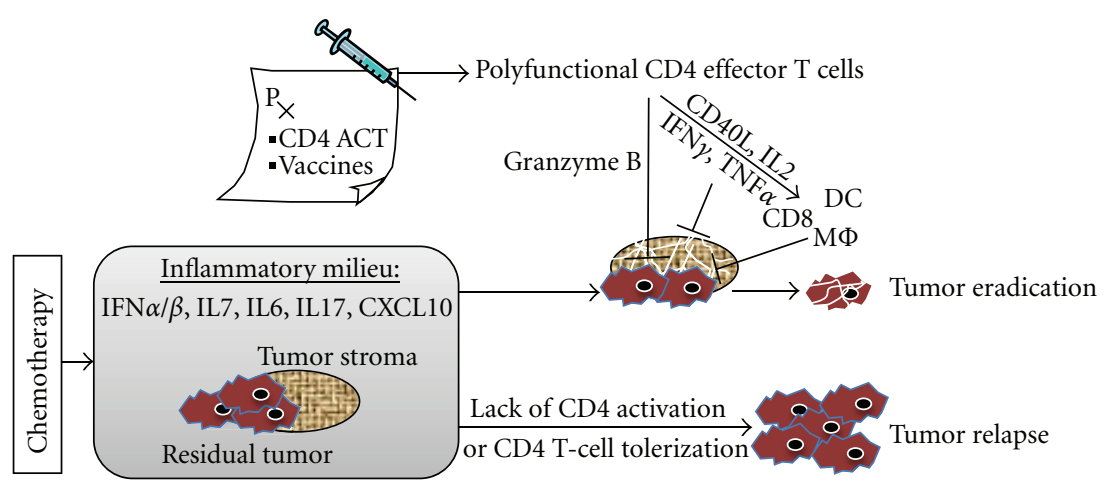

FIGURE 1: Hypothetical model of the mutually reinforcing effect of chemotherapy and antitumor CD4+ effector T cells. Chemotherapy reduces tumor burden, releases tumor antigens, and induces inflammation. In this highly immunogenic milieu created after chemotherapy, therapeutic immunological maneuvers such as adoptive cell therapy (ACT) using tumor-reactive CD4+ T cells or cancer vaccines can lead to the generation of highly activated CD4+ effector T cells with polyfunctional activities. These CD4+ effector T cells act as the "gatekeepers" of the overall antitumor immunity in postchemotherapy hosts, by helping the activation and function of other immune cells (CD8, DC, and macrophage) and directly attacking the tumor cells. In addition, cytokines produced by CD4+ effector T cells (IFN $\gamma$ and TNF $\alpha$ ) may also target and destroy tumor stroma and thus inhibit tumor angiogenesis. These diverse immune responses superimpose to effectively eradicate residual tumors. In contrast, without properly activated CD4+ effector T cells, an effective host antitumor immunity may not be elicited or is not sustainable, leading to tumor persistence and eventual relapse.

expanded by supplying exogenous IL7. Moreover, activating DCs with an anti-CD40 agonist antibody can prevent CD4+ T-cell tolerance [165]. PD1 blockade, currently undergoing extensive clinical trials for a variety of cancers $[166,167]$, is largely expected to restore CD8+ T-cell antitumor function but may as well benefit CD4+ effector T cells. Notably, CTLA4 blockade with ipilimumab, recently approved by FDA for the treatment of late-stage melanoma, has been shown to promote the generation of polyfunctional CD4+ $\mathrm{T}$ cells in response to vaccination [168].

With regard to alleviating Treg-mediated immunosuppression, current approaches only have limited success in therapeutic settings. Low-dose CTX reduces and inactivates Tregs, but doing so only transiently. Application of denileukin diftitox (Ontak) did not result in consistent clinical outcomes $[169,170]$, likely due to its effect on both effector T cells and Tregs. Findings from some recent studies suggest new strategies for disarming Tregs. It has been shown that combined use of CTX and an agonist antibody targeting the costimulatory receptor OX 40 can result in intratumoral apoptosis of Tregs [42]. Moreover, Sharma et al. reported that disrupting the IDO pathway with clinically applicable pharmacological inhibitors can reprogram Tregs to Th17 cells [171].

Altogether, a successful combined chemoimmunotherapy should integrate strategies that target multiple mutually reinforcing immune pathways that converge to attain productive $\mathrm{CD} 4$ effector responses, thereby maintaining a durable and effective antitumor immunity after chemotherapy.

\section{Conclusions}

Although the concept of combined chemoimmunotherapy for cancer can be dated back to at least three decades ago
$[10,11]$, its clinical application started to gain momentum only in recent years when the mechanistic basis for the synergy between chemotherapy and immunotherapy began to be unveiled at the cellular and molecular level. The emerging evidence that chemotherapy can profoundly drive the effector development of tumor-specific CD4+ T cells implicates a new direction for chemoimmunotherapy, which aims to capitalize on the antitumor potential of CD4+ effector T cells. In light of the unique and pivotal roles of tumor-reactive CD4+ effector $\mathrm{T}$ cells, we propose a scenario in which CD4+ effector T cells act as the "gatekeepers" of the overall host antitumor immunity after chemotherapy, whose functional status (polyfunctional versus tolerized) critically determines the outcome between eradication versus recurrence of residual tumors (Figure 1). Further studies are needed to explore additional CD4+ T cell-potentiating anticancer drugs and establish clinically applicable strategies for maximum utilization of the synergy between chemotherapy and antitumor CD4 effector responses in order to achieve durable therapeutic efficacy.

\section{References}

[1] L. A. Emens, J. P. Machiels, R. T. Reilly, and E. M. Jaffee, "Chemotherapy: friend or foe to cancer vaccines?" Current Opinion in Molecular Therapeutics, vol. 3, no. 1, pp. 77-84, 2001.

[2] R. A. Lake and B. W. S. Robinson, "Immunotherapy and chemotherapy-a practical partnership," Nature Reviews Cancer, vol. 5, no. 5, pp. 397-405, 2005.

[3] G. C. Prendergast and E. M. Jaffee, "Cancer immunologists and cancer biologists: why we didn't talk then but need to now," Cancer Research, vol. 67, no. 8, pp. 3500-3504, 2007.

[4] K. Hung, R. Hayashi, A. Lafond-Walker, C. Lowenstein, D. Pardoll, and H. Levitsky, "The central role of CD4+ T cells in the antitumor immune response," Journal of Experimental Medicine, vol. 188, no. 12, pp. 2357-2368, 1998. 
[5] P. A. Antony, C. A. Piccirillo, A. Akpinarli et al., "CD8+ T cell immunity against a tumor/self-antigen is augmented by CD4+ T helper cells and hindered by naturally occurring $\mathrm{T}$ regulatory cells," Journal of Immunology, vol. 174, no. 5, pp. 2591-2601, 2005.

[6] A. Corthay, D. K. Skovseth, K. U. Lundin et al., "Primary antitumor immune response mediated by CD4+ T cells," Immunity, vol. 22, no. 3, pp. 371-383, 2005.

[7] A. Perez-Diez, N. T. Joncker, K. Choi et al., "CD4 cells can be more efficient at tumor rejection than CD8 cells," Blood, vol. 109, no. 12, pp. 5346-5354, 2007.

[8] N. N. Hunder, H. Wallen, J. Cao et al., "Treatment of metastatic melanoma with autologous $\mathrm{CD} 4+\mathrm{T}$ cells against NYESO-1," The New England Journal of Medicine, vol. 358, no. 25, pp. 2698-2703, 2008.

[9] K. Rakhra, P. Bachireddy, T. Zabuawala et al., "CD4+ T cells contribute to the remodeling of the microenvironment required for sustained tumor regression upon oncogene inactivation," Cancer Cell, vol. 18, no. 5, pp. 485-498, 2010.

[10] T. Borsos, R. C. Bast Jr., and S. H. Ohanian, "Induction of tumor immunity by intratumoral chemotherapy," Annals of the New York Academy of Sciences, vol. 276, pp. 565-572, 1976.

[11] A. Fefer, A. B. Einstein, and M. A. Cheever, "Adoptive chemoimmunotherapy of cancer in animals: a review of results, principles, and problems," Annals of the New York Academy of Sciences, vol. 277, pp. 492-504, 1976.

[12] L. Zitvogel, L. Apetoh, F. Ghiringhelli, F. André, A. Tesniere, and G. Kroemer, "The anticancer immune response: indispensable for therapeutic success?" Journal of Clinical Investigation, vol. 118, no. 6, pp. 1991-2001, 2008.

[13] M. Obeid, A. Tesniere, F. Ghiringhelli et al., "Calreticulin exposure dictates the immunogenicity of cancer cell death," Nature Medicine, vol. 13, no. 1, pp. 54-61, 2007.

[14] L. Apetoh, F. Ghiringhelli, A. Tesniere et al., "Toll-like receptor 4-dependent contribution of the immune system to anticancer chemotherapy and radiotherapy," Nature Medicine, vol. 13, no. 9, pp. 1050-1059, 2007.

[15] F. Ghiringhelli, L. Apetoh, A. Tesniere et al., "Activation of the NLRP3 inflammasome in dendritic cells induces IL$1 \beta$-dependent adaptive immunity against tumors," Nature Medicine, vol. 15, no. 10, pp. 1170-1178, 2009.

[16] J. L. Guerriero, D. Ditsworth, J. M. Catanzaro et al., "DNA alkylating therapy induces tumor regression through an HMGB1-mediated activation of innate immunity," Journal of Immunology, vol. 186, no. 6, pp. 3517-3526, 2011.

[17] G. Schiavoni, A. Sistigu, M. Valentini et al., "Cyclophosphamide synergizes with type I interferons through systemic dendritic cell reactivation and induction of immunogenic tumor apoptosis," Cancer Research, vol. 71, no. 3, pp. 768$778,2011$.

[18] A. K. Nowak, R. A. Lake, A. L. Marzo et al., "Induction of tumor cell apoptosis in vivo increases tumor antigen crosspresentation, cross-priming rather than cross-tolerizing host tumor-specific CD8 T cells," Journal of Immunology, vol. 170, no. 10, pp. 4905-4913, 2003.

[19] D. Hanahan and R. A. Weinberg, "Hallmarks of cancer: the next generation," Cell, vol. 144, pp. 646-674, 2011.

[20] H. T. Khong and N. P. Restifo, "Natural selection of tumor variants in the generation of "tumor escape" phenotypes," Nature Immunology, vol. 3, no. 11, pp. 999-1005, 2002.

[21] G. P. Dunn, A. T. Bruce, H. Ikeda, L. J. Old, and R. D. Schreiber, "Cancer immunoediting: from immunosurveillance to tumor escape," Nature Immunology, vol. 3, no. 11, pp. 991998, 2002.

[22] W. Zou, "Immunosuppressive networks in the tumour environment and their therapeutic relevance," Nature Reviews Cancer, vol. 5, no. 4, pp. 263-274, 2005.

[23] M. E. C. Lutsiak, R. T. Semnani, R. De Pascalis, S. V. S. Kashmiri, J. Schlom, and H. Sabzevari, "Inhibition of $\mathrm{CD} 4+25+\mathrm{T}$ regulatory cell function implicated in enhanced immune response by low-dose cyclophosphamide," Blood, vol. 105, no. 7, pp. 2862-2868, 2005.

[24] R. G. Van Der Most, A. J. Currie, S. Mahendran et al., “Tumor eradication after cyclophosphamide depends on concurrent depletion of regulatory T cells: a role for cycling TNFR2expressing effector-suppressor $\mathrm{T}$ cells in limiting effective chemotherapy," Cancer Immunology, Immunotherapy, vol. 58, no. 8, pp. 1219-1228, 2009.

[25] M. Awwad and R. J. North, "Cyclophosphamide (Cy)-facilitated adoptive immunotherapy of a Cy-resistant tumour. Evidence that Cy permits the expression of adoptive T-cell mediated immunity by removing suppressor $\mathrm{T}$ cells rather than by reducing tumour burden," Immunology, vol. 65, no. 1, pp. 87-92, 1988.

[26] F. Ghiringhelli, C. Menard, P. E. Puig et al., "Metronomic cyclophosphamide regimen selectively depletes CD4 $+\mathrm{CD} 25+$ regulatory $\mathrm{T}$ cells and restores $\mathrm{T}$ and $\mathrm{NK}$ effector functions in end stage cancer patients," Cancer Immunology, Immunotherapy, vol. 56, no. 5, pp. 641-648, 2007.

[27] A. M. Ercolini, B. H. Ladle, E. A. Manning et al., "Recruitment of latent pools of high-avidity CD8+ $\mathrm{T}$ cells to the antitumor immune response," Journal of Experimental Medicine, vol. 201, no. 10, pp. 1591-1602, 2005.

[28] T. Nakahara, H. Uchi, A. M. Lesokhin et al., "Cyclophosphamide enhances immunity by modulating the balance of dendritic cell subsets in lymphoid organs," Blood, vol. 115, no. 22, pp. 4384-4392, 2010.

[29] E. Suzuki, V. Kapoor, A. S. Jassar, L. R. Kaiser, and S. M. Albelda, "Gemcitabine selectively eliminates splenic Gr$1+/ \mathrm{CD} 11 \mathrm{~b}+$ myeloid suppressor cells in tumor-bearing animals and enhances antitumor immune activity," Clinical Cancer Research, vol. 11, no. 18, pp. 6713-6721, 2005.

[30] J. P. H. Machiels, R. Todd Reilly, L. A. Emens et al., "Cyclophosphamide, doxorubicin, and paclitaxel enhance the antitumor immune response of granulocyte/macrophage-colony stimulating factor-secreting whole-cell vaccines in HER-2/neu tolerized mice," Cancer Research, vol. 61, no. 9, pp. 3689-3697, 2001.

[31] C. A. Klebanoff, H. T. Khong, P. A. Antony, D. C. Palmer, and N. P. Restifo, "Sinks, suppressors and antigen presenters: how lymphodepletion enhances T cell-mediated tumor immunotherapy," Trends in Immunology, vol. 26, no. 2, pp. 111-117, 2005.

[32] L. Gattinoni, S. E. Finkelstein, C. A. Klebanoff et al., "Removal of homeostatic cytokine sinks by lymphodepletion enhances the efficacy of adoptively transferred tumor-specific CD8+ T cells," Journal of Experimental Medicine, vol. 202, no. 7, pp. 907-912, 2005.

[33] L. Bracci, F. Moschella, P. Sestili et al., "Cyclophosphamide enhances the antitumor efficacy of adoptively transferred immune cells through the induction of cytokine expression, B-cell and T-cell homeostatic proliferation, and specific tumor infiltration," Clinical Cancer Research, vol. 13, no. 2 I, pp. 644-653, 2007. 
[34] F. Moschella, M. Valentini, E. Aricò et al., "Unraveling cancer chemoimmunotherapy mechanisms by gene and protein expression profiling of responses to cyclophosphamide," Cancer Research, vol. 71, no. 10, pp. 3528-3539, 2011.

[35] M. Montoya, G. Schiavoni, F. Mattei et al., "Type I interferons produced by dendritic cells promote their phenotypic and functional activation," Blood, vol. 99, no. 9, pp. 3263-3271, 2002.

[36] G. Schiavoni, F. Mattei, T. Di Pucchio et al., "Cyclophosphamide induces type I interferon and augments the number of CD44(hi) T lymphocytes in mice: implications for strategies of chemoimmunotherapy of cancer," Blood, vol. 95, no. 6, pp. 2024-2030, 2000.

[37] J. M. Curtsinger, J. O. Valenzuela, P. Agarwal, D. Lins, and M. F. Mescher, "Cutting edge: type I IFNs provide a third signal to CD8 $\mathrm{T}$ cells to stimulate clonal expansion and differentiation," Journal of Immunology, vol. 174, no. 8, pp. 4465-4469, 2005.

[38] M. L. Salem, A. N. Kadima, S. A. El-Naggar et al., "Defining the ability of cyclophosphamide preconditioning to enhance the antigen-specific CD8+ T-cell response to peptide vaccination: creation of a beneficial host microenvironment involving type I IFNs and myeloid cells," Journal of Immunotherapy, vol. 30, no. 1, pp. 40-53, 2007.

[39] B. A. Pockaj, R. M. Sherry, J. P. Wei et al., "Localization of 11 indium-labeled tumor infiltrating lymphocytes to tumor in patients receiving adoptive immunotherapy: augmentation with cyclophosphamide and correlation with response," Cancer, vol. 73, no. 6, pp. 1731-1737, 1994.

[40] R. Ramakrishnan, D. Assudani, S. Nagaraj et al., "Chemotherapy enhances tumor cell susceptibility to CTL-mediated killing during cancer immunotherapy in mice," Journal of Clinical Investigation, vol. 120, no. 4, pp. 1111-1124, 2010.

[41] R. G. van der Most, A. J. Currie, A. L. Cleaver et al., "Cyclophosphamide chemotherapy sensitizes tumor cells to TRAILdependent CD8 T cell-mediated immune attack resulting in suppression of tumor growth," PLoS ONE, vol. 4, no. 9, article e6982, 2009.

[42] D. Hirschhorn-Cymerman, G. A. Rizzuto, T. Merghoub et al., "OX40 engagement and chemotherapy combination provides potent antitumor immunity with concomitant regulatory T cell apoptosis," Journal of Experimental Medicine, vol. 206, no. 5, pp. 1103-1116, 2009.

[43] M. J. Turk, J. A. Guevara-Patiño, G. A. Rizzuto, M. E. Engelhorn, and A. N. Houghton, "Concomitant tumor immunity to a poorly immunogenic melanoma is prevented by regulatory T cells," Journal of Experimental Medicine, vol. 200, no. 6, pp. 771-782, 2004.

[44] M. L. Salem, S. A. El-Naggar, and D. J. Cole, "Cyclophosphamide induces bone marrow to yield higher numbers of precursor dendritic cells in vitro capable of functional antigen presentation to T cells in vivo," Cellular Immunology, vol. 261, no. 2, pp. 134-143, 2010.

[45] V. Radojcic, K. B. Bezak, M. Skarica et al., "Cyclophosphamide resets dendritic cell homeostasis and enhances antitumor immunity through effects that extend beyond regulatory T cell elimination," Cancer Immunology, Immunotherapy, vol. 59, no. 1, pp. 137-148, 2010.

[46] S. L. Constant and K. Bottomly, "Induction of TH1 and TH2 CD4+ T cell responses: the alternative approaches," Annual Review of Immunology, vol. 15, pp. 297-322, 1997.

[47] J. Zhu, H. Yamane, and W. E. Paul, "Differentiation of effector CD4+ T cell populations," Annual Review of Immunology, vol. 28, pp. 445-489, 2010.
[48] J. O'Shea and W. E. Paul, "Mechanisms underlying lineage commitment and plasticity of helper CD4+ T cells," Science, vol. 327, no. 5969, pp. 1098-1102, 2010.

[49] D. G. DeNardo, J. B. Barreto, P. Andreu et al., "CD4+ T cells regulate pulmonary metastasis of mammary carcinomas by enhancing protumor properties of macrophages," Cancer Cell, vol. 16, no. 2, pp. 91-102, 2009.

[50] T. Nishimura, K. Iwakabe, M. Sekimoto et al., "Distinct role of antigen-specific T helper type 1 (Th1) and Th2 cells in tumor eradication in vivo," Journal of Experimental Medicine, vol. 190, no. 5, pp. 617-627, 1999.

[51] G. Murugaiyan and B. Saha, "Protumor vs antitumor functions of IL-17," Journal of Immunology, vol. 183, no. 7, pp. 4169-4175, 2009.

[52] P. Muranski, A. Boni, P. A. Antony et al., "Tumor-specific Th17-polarized cells eradicate large established melanoma," Blood, vol. 112, no. 2, pp. 362-373, 2008.

[53] N. Martin-Orozco, P. Muranski, Y. Chung et al., "T helper 17 cells promote cytotoxic T cell activation in tumor immunity," Immunity, vol. 31, no. 5, pp. 787-798, 2009.

[54] S. Wu, K. J. Rhee, E. Albesiano et al., "A human colonic commensal promotes colon tumorigenesis via activation of T helper type 17 T cell responses," Nature Medicine, vol. 15, no. 9, pp. 1016-1022, 2009.

[55] L. Wang, T. Yi, M. Kortylewski, D. M. Pardoll, D. Zeng, and $\mathrm{H}$. Yu, "IL-17 can promote tumor growth through an IL-6Stat3 signaling pathway," Journal of Experimental Medicine, vol. 206, no. 7, pp. 1457-1464, 2009.

[56] G. Zhou, C. G. Drake, and H. I. Levitsky, "Amplification of tumor-specific regulatory $\mathrm{T}$ cells following therapeutic cancer vaccines," Blood, vol. 107, no. 2, pp. 628-636, 2006.

[57] T. Hiura, H. Kagamu, S. Miura et al., "Both regulatory T cells and antitumor effector $\mathrm{T}$ cells are primed in the same draining lymph nodes during tumor progression," Journal of Immunology, vol. 175, no. 8, pp. 5058-5066, 2005.

[58] S. A. Quezada, K. S. Peggs, M. A. Curran, and J. P. Allison, "CTLA4 blockade and GM-CSF combination immunotherapy alters the intratumor balance of effector and regulatory T cells," Journal of Clinical Investigation, vol. 116, no. 7, pp. 1935-1945, 2006.

[59] F. Ghiringhelli, C. Ménard, M. Terme et al., "CD4+CD25+ regulatory $\mathrm{T}$ cells inhibit natural killer cell functions in a transforming growth factor- $\beta$-dependent manner," Journal of Experimental Medicine, vol. 202, no. 8, pp. 1075-1085, 2005.

[60] S. Roux, L. Apetoh, F. Chalmin et al., "CD4+CD25+ Tregs control the TRAIL-dependent cytotoxicity of tumorinfiltrating DCs in rodent models of colon cancer," Journal of Clinical Investigation, vol. 118, no. 11, pp. 3751-3761, 2008.

[61] P. D. Greenberg, M. A. Cheever, and A. Fefer, "Eradication of disseminated murine leukemia by chemoimmunotherapy with cyclophosphamide and adoptively transferred immune syngeneic Lyt-1+2- lymphocytes," Journal of Experimental Medicine, vol. 154, no. 3, pp. 952-963, 1981.

[62] E. Proietti, G. Greco, B. Garrone et al., "Importance of cyclophosphamide-induced bystander effect on $\mathrm{T}$ cells for a successful tumor eradication in response to adoptive immunotherapy in mice," Journal of Clinical Investigation, vol. 101, no. 2, pp. 429-441, 1998.

[63] K. Chamoto, T. Tsuji, H. Funamoto et al., "Potentiation of tumor eradication by adoptive immunotherapy with T-cell receptor gene-transduced T-helper type 1 cells," Cancer Research, vol. 64, no. 1, pp. 386-390, 2004.

[64] Z. C. Ding, B. R. Blazar, A. L. Mellor, D. H. Munn, and G. Zhou, "Chemotherapy rescues tumor-driven aberrant CD4+ 
T-cell differentiation and restores an activated polyfunctional helper phenotype," Blood, vol. 115, no. 12, pp. 2397-2406, 2010.

[65] P. Matar, V. R. Rozados, S. I. Gervasoni, and O. G. Scharovsky, "Th2/Th1 switch induced by a single low dose of cyclophosphamide in a rat metastatic lymphoma model," Cancer Immunology, Immunotherapy, vol. 50, no. 11, pp. 588596, 2002.

[66] S. A. Quezada, T. R. Simpson, K. S. Peggs et al., "Tumorreactive $\mathrm{CD} 4+\mathrm{T}$ cells develop cytotoxic activity and eradicate large established melanoma after transfer into lymphopenic hosts," Journal of Experimental Medicine, vol. 207, no. 3, pp. 637-650, 2010.

[67] S. Viaud, C. Flament, M. Zoubir et al., "Cyclophosphamide induces differentiation of Th17 cells in cancer patients," Cancer Research, vol. 71, no. 3, pp. 661-665, 2011.

[68] Y. Ma, L. Aymeric, C. Locher et al., "Contribution of IL-17-producing $\gamma \delta \mathrm{T}$ cells to the efficacy of anticancer chemotherapy," Journal of Experimental Medicine, vol. 208, no. 3, pp. 491-503, 2011.

[69] A. Le Bon and D. F. Tough, "Links between innate and adaptive immunity via type I interferon," Current Opinion in Immunology, vol. 14, no. 4, pp. 432-436, 2002.

[70] M. P. Longhi, C. Trumpfheller, J. Idoyaga et al., "Dendritic cells require a systemic type I interferon response to mature and induce CD4+ Th1 immunity with poly IC as adjuvant," Journal of Experimental Medicine, vol. 206, no. 7, pp. 15891602, 2009.

[71] L. Pace, S. Vitale, B. Dettori et al., "APC activation by IFN- $\alpha$ decreases regulatory T cell and enhances Th cell functions," Journal of Immunology, vol. 184, no. 11, pp. 5969-5979, 2010.

[72] M. Pellegrini, T. Calzascia, A. R. Elford et al., "Adjuvant IL-7 antagonizes multiple cellular and molecular inhibitory networks to enhance immunotherapies," Nature Medicine, vol. 15, no. 5, pp. 528-536, 2009.

[73] S. A. Rosenberg, C. Sportès, M. Ahmadzadeh et al., "IL-7 administration to humans leads to expansion of CD8+ and CD4+ cells but a relative decrease of CD4+ T-regulatory cells," Journal of Immunotherapy, vol. 29, no. 3, pp. 313-319, 2006.

[74] A. Andersson, S. C. Yang, M. Huang et al., "IL-7 promotes CXCR3 ligand-dependent $\mathrm{T}$ cell antitumor reactivity in lung cancer," Journal of Immunology, vol. 182, no. 11, pp. 69516958, 2009.

[75] S. R. M. Bennett, F. R. Carbone, F. Karamalis, R. A. Flavell, J. F. A. P. Miller, and W. R. Heath, "Help for cytotoxic-T-cell responses is mediated by CD4O signalling," Nature, vol. 393, no. 6684, pp. 478-480, 1998.

[76] J. P. Ridge, F. Di Rosa, and P. Matzinger, "A conditioned dendritic cell can be a temporal bridge between a CD4+ Thelper and a T-killer cell," Nature, vol. 393, no. 6684, pp. 474478, 1998.

[77] S. P. Schoenberger, R. E. M. Toes, E. I. H. Van Dervoort, R. Offringa, and C. J. M. Melief, "T-cell help for cytotoxic T lymphocytes is mediated by CD40-CD4OL interactions," Nature, vol. 393, no. 6684, pp. 480-483, 1998.

[78] K. A. Shafer-Weaver, S. K. Watkins, M. J. Anderson et al., "Immunity to murine prostatic tumors: continuous provision of T-cell help prevents CD8 T-cell tolerance and activates tumor-infiltrating dendritic cells," Cancer Research, vol. 69, no. 15, pp. 6256-6264, 2009.

[79] Y. C. Nesbeth, D. G. Martinez, S. Toraya et al., "CD4+ $\mathrm{T}$ cells elicit host immune responses to MHC class II ovarian cancer through CCL5 secretion and CD40-mediated licensing of dendritic cells," Journal of Immunology, vol. 184, no. 10 , pp. 5654-5662, 2010.

[80] A. L. Marzo, B. F. Kinnear, R. A. Lake et al., "Tumor-specific CD4+ T cells have a major 'post-licensing' role in CTL mediated anti-tumor immunity," Journal of Immunology, vol. 165, no. 11, pp. 6047-6055, 2000.

[81] Y. Nakanishi, B. Lu, C. Gerard, and A. Iwasaki, "CD8 + T lymphocyte mobilization to virus-infected tissue requires CD4 + T-cell help," Nature, vol. 462, no. 7272, pp. 510-513, 2009.

[82] R. Bos and L. A. Sherman, "CD4+ T-cell help in the tumor milieu is required for recruitment and cytolytic function of CD8+ T lymphocytes," Cancer Research, vol. 70, no. 21, pp. 8368-8377, 2010.

[83] Z. Qin and T. Blankenstein, "CD4+ T cell-mediated tumor rejection involves inhibition of angiogenesis that is dependent on IFN $\gamma$ receptor expression by nonhematopoietic cells," Immunity, vol. 12, no. 6, pp. 677-686, 2000.

[84] B. Zhang, T. Karrison, D. A. Rowley, and H. Schreiber, "IFN$\gamma$ - and TNF-dependent bystander eradication of antigen-loss variants in established mouse cancers," Journal of Clinical Investigation, vol. 118, no. 4, pp. 1398-1404, 2008.

[85] O. A. W. Haabeth, K. B. Lorvik, C. Hammarström et al., "Inflammation driven by tumour-specific Th1 cells protects against B-cell cancer," Nature Communications, vol. 2, no. 1, article 240, 2011.

[86] G. L. Beatty, E. G. Chiorean, M. P. Fishman et al., "CD40 agonists alter tumor stroma and show efficacy against pancreatic carcinoma in mice and humans," Science, vol. 331, no. 6024, pp. 1612-1616, 2011.

[87] A. Mantovani, P. Allavena, A. Sica, and F. Balkwill, "Cancerrelated inflammation," Nature, vol. 454, no. 7203, pp. 436444, 2008.

[88] S. I. Grivennikov, F. R. Greten, and M. Karin, "Immunity, inflammation, and cancer," Cell, vol. 140, no. 6, pp. 883-899, 2010.

[89] E. Von Stebut, J. M. Ehrchen, Y. Belkaid et al., "Interleukin $1 \alpha$ promotes TH1 differentiation and inhibits disease progression in Leishmania major-susceptible BALB/c mice," Journal of Experimental Medicine, vol. 198, no. 2, pp. 191-199, 2003.

[90] S. Z. Ben-Sasson, J. Hu-Li, J. Quiel et al., "IL-1 acts directly on CD4 $\mathrm{T}$ cells to enhance their antigen-driven expansion and differentiation," Proceedings of the National Academy of Sciences of the United States of America, vol. 106, no. 17, pp. 7119-7124, 2009.

[91] K. M. E. Gallagher, S. Lauder, I. W. Rees, A. M. Gallimore, and A. J. Godkin, "Type I interferon (IFN $\alpha$ ) acts directly on human memory CD4+ $\mathrm{T}$ cells altering their response to antigen," Journal of Immunology, vol. 183, no. 5, pp. 29152920, 2009.

[92] C. Havenar-Daughton, G. A. Kolumam, and K. MuraliKrishna, "Cutting edge: the direct action of type I IFN on $\mathrm{CD} 4 \mathrm{~T}$ cells is critical for sustaining clonal expansion in response to a viral but not a bacterial infection," Journal of Immunology, vol. 176, no. 6, pp. 3315-3319, 2006.

[93] A. G. Sikora, N. Jaffarzad, Y. Hailemichael et al., "IFN- $\alpha$ enhances peptide vaccine-induced CD8+ T cell numbers, effector function, and antitumor activity," Journal of Immunology, vol. 182, no. 12, pp. 7398-7407, 2009.

[94] C. Pasare and R. Medzhitov, "Toll pathway-dependent blockade of CD4+CD25+ T cell-mediated suppression by dendritic cells," Science, vol. 299, no. 5609, pp. 1033-1036, 2003.

[95] B. Baban, P. R. Chandler, M. D. Sharma et al., "IDO activates regulatory $\mathrm{T}$ cells and blocks their conversion into Th17-like 
T cells," Journal of Immunology, vol. 183, no. 4, pp. 24752483, 2009.

[96] M. D. Sharma, D. Y. Hou, Y. Liu et al., "Indoleamine 2,3dioxygenase controls conversion of Foxp3+ Tregs to TH17like cells in tumor-draining lymph nodes," Blood, vol. 113, no. 24, pp. 6102-6111, 2009.

[97] L. Li, J. Kim, and V. A. Boussiotis, "IL- $1 \beta$-mediated signals preferentially drive conversion of regulatory $\mathrm{T}$ cells but not conventional T cells into IL-17-producing cells," Journal of Immunology, vol. 185, no. 7, pp. 4148-4153, 2010.

[98] X. Song, E. Voronov, T. Dvorkin et al., "Differential effects of IL- $1 \alpha$ and IL- $1 \beta$ on Tumorigenicity Patterns and Invasiveness," Journal of Immunology, vol. 171, no. 12, pp. 6448-6456, 2003.

[99] F. Vidal-Vanaclocha, C. Amezaga, A. Asumendi, G. Kaplanski, and C. A. Dinarello, "Interleukin-1 receptor blockade reduces the number and size of murine B16 melanoma hepatic metastases," Cancer Research, vol. 54, no. 10, pp. 2667-2672, 1994.

[100] E. Voronov, D. S. Shouval, Y. Krelin et al., "IL-1 is required for tumor invasiveness and angiogenesis," Proceedings of the National Academy of Sciences of the United States of America, vol. 100, no. 5, pp. 2645-2650, 2003.

[101] P. Sansone, G. Storci, S. Tavolari et al., "IL-6 triggers malignant features in mammospheres from human ductal breast carcinoma and normal mammary gland," Journal of Clinical Investigation, vol. 117, no. 12, pp. 3988-4002, 2007.

[102] S. P. Gao, K. G. Mark, K. Leslie et al., "Mutations in the EGFR kinase domain mediate STAT3 activation via IL-6 production in human lung adenocarcinomas," Journal of Clinical Investigation, vol. 117, no. 12, pp. 3846-3856, 2007.

[103] S. Grivennikov, E. Karin, J. Terzic et al., "IL-6 and Stat3 are required for survival of intestinal epithelial cells and development of colitis-associated cancer," Cancer Cell, vol. 15, no. 2, pp. 103-113, 2009.

[104] S. K. Bunt, P. Sinha, V. K. Clements, J. Leips, and S. OstrandRosenberg, "Inflammation induces myeloid-derived suppressor cells that facilitate tumor progression," Journal of Immunology, vol. 176, no. 1, pp. 284-290, 2006.

[105] S. K. Bunt, L. Yang, P. Sinha, V. K. Clements, J. Leips, and S. Ostrand-Rosenberg, "Reduced inflammation in the tumor microenvironment delays the accumulation of myeloidderived suppressor cells and limits tumor progression," Cancer Research, vol. 67, no. 20, pp. 10019-10026, 2007.

[106] X. Song, Y. Krelin, T. Dvorkin et al., "CD11b+/Gr-1+ immature myeloid cells mediate suppression of T cells in mice bearing tumors of IL- $1 \beta$-secreting cells," Journal of Immunology, vol. 175, no. 12, pp. 8200-8208, 2005.

[107] W. Zou and L. Chen, "Inhibitory B7-family molecules in the tumour microenvironment," Nature Reviews Immunology, vol. 8, no. 6, pp. 467-477, 2008.

[108] S. Terawaki, S. Chikuma, S. Shibayama et al., "IFN-alpha directly promotes programmed cell death-1 transcription and limits the duration of T cell-mediated immunity," The Journal of Immunology, vol. 186, pp. 2772-2779, 2011.

[109] B. Baban, A. M. Hansen, P. R. Chandler et al., "A minor population of splenic dendritic cells expressing CD19 mediates IDO-dependent $\mathrm{T}$ cell suppression via type I IFN signaling following B7 ligation," International Immunology, vol. 17, no. 7, pp. 909-919, 2005.

[110] A. J. Muller, M. D. Sharma, P. R. Chandler et al., "Chronic inflammation that facilitates tumor progression creates local immune suppression by inducing indoleamine 2,3 dioxygenase," Proceedings of the National Academy of Sciences of the
United States of America, vol. 105, no. 44, pp. 17073-17078, 2008.

[111] L. A. Gilbert and M. T. Hemann, "DNA damage-mediated induction of a chemoresistant niche," Cell, vol. 143, no. 3, pp. 355-366, 2010.

[112] D. L. Porter, B. L. Levine, M. Kalos, A. Bagg, and C. H. June, "Chimeric antigen receptor-modified T cells in chronic lymphoid leukemia," The New England Journal of Medicine, vol. 365, no. 8, pp. 725-733, 2011.

[113] S. R. Mattarollo, S. Loi, H. Duret, Y. Ma, L. Zitvogel, and M. J. Smyth, "Pivotal role of innate and adaptive immunity in anthracycline chemotherapy of established tumors," Cancer Research, vol. 71, no. 14, pp. 4809-4820, 2011.

[114] B. J. Nickoloff, Y. Ben-Neriah, and E. Pikarsky, "Inflammation and cancer: is the link as simple as we think?" Journal of Investigative Dermatology, vol. 124, pp. 10-14, 2005.

[115] E. J. Schattner, J. Mascarenhas, J. Bishop et al., "CD4+ T-cell induction of Fas-mediated apoptosis in Burkitt's lymphoma B cells," Blood, vol. 88, no. 4, pp. 1375-1382, 1996.

[116] W. D. Thomas and P. Hersey, "TNF-related apoptosis-inducing ligand (TRAIL) induces apoptosis in Fas ligandresistant melanoma cells and mediates CD4 T cell killing of target cells," Journal of Immunology, vol. 161, no. 5, pp. 21952200, 1998.

[117] J. H. Finke, P. Rayman, J. Alexander et al., "Characterization of the cytolytic activity of CD4+ and CD8+ tumorinfiltrating lymphocytes in human renal cell carcinoma," Cancer Research, vol. 50, no. 8, pp. 2363-2370, 1990.

[118] N. S. Williams and V. H. Engelhard, "Identification of a population of CD4+ CTL that utilizes a perforin- rather than a Fas ligand-dependent cytotoxic mechanism," Journal of Immunology, vol. 156, no. 1, pp. 153-159, 1996.

[119] E. S. Schultz, B. Lethe, C. L. Cambiaso et al., "A MAGE-A3 peptide presented by HLA-DP4 is recognized on tumor cells by CD4+ cytolytic T lymphocytes," Cancer Research, vol. 60, no. 22, pp. 6272-6275, 2000.

[120] Q. Sun, R. L. Burton, and K. G. Lucas, "Cytokine production and cytolytic mechanism of CD4+ cytotoxic T lymphocytes in ex vivo expanded therapeutic Epstein-Barr virus-specific T-cell cultures," Blood, vol. 99, no. 9, pp. 3302-3309, 2002.

[121] V. Appay, J. J. Zaunders, L. Papagno et al., "Characterization of CD4+ CTLs ex vivo," Journal of Immunology, vol. 168, no. 11, pp. 5954-5958, 2002.

[122] Y. Xie, A. Akpinarli, C. Maris et al., "Naive tumor-specific $\mathrm{CD} 4+\mathrm{T}$ cells differentiated in vivo eradicate established melanoma," Journal of Experimental Medicine, vol. 207, no. 3, pp. 651-667, 2010.

[123] H. Z. Qui, A. T. Hagymasi, S. Bandyopadhyay et al., "CD134 plus CD137 dual costimulation induces eomesodermin in CD4 T cells to program cytotoxic Th1 differentiation," Journal of Immunology, vol. 187, no. 7, pp. 3555-3564, 2011.

[124] L. H. Butterfield, A. Ribas, V. B. Dissette et al., "Determinant spreading associated with clinical response in dendritic cellbased immunotherapy for malignant melanoma," Clinical Cancer Research, vol. 9, no. 3, pp. 998-1008, 2003.

[125] C. Lurquin, B. Lethé, E. De Plaen et al., "Contrasting frequencies of antitumor and anti-vaccine $\mathrm{T}$ cells in metastases of a melanoma patient vaccinated with a MAGE tumor antigen," Journal of Experimental Medicine, vol. 201, no. 2, pp. 249257, 2005.

[126] V. Corbière, J. Chapiro, V. Stroobant et al., "Antigen spreading contributes to MAGE vaccination-induced regression of melanoma metastases," Cancer Research, vol. 71, no. 4, pp. 1253-1262, 2011. 
[127] P. D. Greenberg, D. E. Kern, and M. A. Cheever, "Therapy of disseminated murine leukemia with cyclophosphamide and immune Lyt-1+,2- T cells. Tumor eradication does not require participation of cytotoxic T cells," Journal of Experimental Medicine, vol. 161, no. 5, pp. 1122-1134, 1985.

[128] F. Ossendorp, E. Mengedé, M. Camps, R. Filius, and C. J. M. Melief, "Specific T helper cell requirement for optimal induction of cytotoxic $\mathrm{T}$ lymphocytes against major histocompatibility complex class II negative tumors," Journal of Experimental Medicine, vol. 187, no. 5, pp. 693-702, 1998.

[129] M. E. Dudley, J. R. Wunderlich, P. F. Robbins et al., "Cancer regression and autoimmunity in patients after clonal repopulation with antitumor lymphocytes," Science, vol. 298, no. 5594, pp. 850-854, 2002.

[130] K. Chamoto, A. Kosaka, T. Tsuji et al., "Critical role of the Th1/Tcl circuit for the generation of tumor-specific CTL during tumor eradication in vivo by Th1-cell therapy," Cancer Science, vol. 94, no. 10, pp. 924-928, 2003.

[131] A. P. Rapoport, E. A. Stadtmauer, N. Aqui et al., "Restoration of immunity in lymphopenic individuals with cancer by vaccination and adoptive T-cell transfer," Nature Medicine, vol. 11, no. 11, pp. 1230-1237, 2005.

[132] L. X. Wang, S. Shu, M. L. Disis, and G. E. Plautz, "Adoptive transfer of tumor-primed, in vitro-activated, CD4+ $\mathrm{T}$ effector cells (TEs) combined with CD8+ TEs provides intratumoral TE proliferation and synergistic antitumor response," Blood, vol. 109, no. 11, pp. 4865-4876, 2007.

[133] A. Schietinger, M. Philip, R. B. Liu, K. Schreiber, and H. Schreiber, "Bystander killing of cancer requires the cooperation of CD4+ and CD8+ T cells during the effector phase," Journal of Experimental Medicine, vol. 207, no. 11, pp. 2469-2477, 2010.

[134] K. Chamoto, D. Wakita, Y. Narita et al., "An essential role of antigen-presenting cell/T-helper type 1 cell-cell interactions in draining lymph node during complete eradication of class II-negative tumor tissue by T-helper type 1 cell therapy," Cancer Research, vol. 66, no. 3, pp. 1809-1817, 2006.

[135] M. J. Goldstein, B. Varghese, J. D. Brody et al., "A CpGloaded tumor cell vaccine induces antitumor CD4+ T cells that are effective in adoptive therapy for large and established tumors," Blood, vol. 117, no. 1, pp. 118-127, 2011.

[136] K. Staveley-O'Carroll, E. Sotomayor, J. Montgomery et al., "Induction of antigen-specific T cell anergy: an early event in the course of tumor progression," Proceedings of the National Academy of Sciences of the United States of America, vol. 95, no. 3, pp. 1178-1183, 1998.

[137] M. Kuczma, M. Kopij, I. Pawlikowska, C. Y. Wang, G. A. Rempala, and P. Kraj, "Intratumoral convergence of the TCR repertoires of effector and Foxp3+ CD4+ t cells," PLoS ONE, vol. 5, no. 10, article e13623, 2010.

[138] G. Zhou and H. I. Levitsky, "Natural regulatory T cells and de novo-induced regulatory $\mathrm{T}$ cells contribute independently to tumor-specific tolerance," Journal of Immunology, vol. 178, no. 4, pp. 2155-2162, 2007.

[139] B. Valzasina, S. Piconese, C. Guiducci, and M. P. Colombo, "Tumor-induced expansion of regulatory $\mathrm{T}$ cells by conversion of CD4+CD25- lymphocytes is thymus and proliferation independent," Cancer Research, vol. 66, no. 8, pp. 44884495, 2006.

[140] J. A. Hill, J. A. Hall, C. M. Sun et al., "Retinoic acid enhances Foxp3 induction indirectly by relieving inhibition from CD4+CD44hi cells," Immunity, vol. 29, no. 5, pp. 758-770, 2008.
[141] D. Caretto, S. D. Katzman, A. V. Villarino, E. Gallo, and A. K. Abbas, "Cutting edge: the Th1 response inhibits the generation of peripheral regulatory T cells," Journal of Immunology, vol. 184, no. 1, pp. 30-34, 2010.

[142] C. E. Tadokoro, G. Shakhar, S. Shen et al., "Regulatory T cells inhibit stable contacts between CD4+ T cells and dendritic cells in vivo," Journal of Experimental Medicine, vol. 203, no. 3, pp. 505-511, 2006.

[143] Q. Tang, J. Y. Adams, A. J. Tooley et al., "Visualizing regulatory $\mathrm{T}$ cell control of autoimmune responses in nonobese diabetic mice," Nature Immunology, vol. 7, no. 1, pp. 83-92, 2006.

[144] T. R. Mempel, M. J. Pittet, K. Khazaie et al., "Regulatory T cells reversibly suppress cytotoxic $\mathrm{T}$ cell function independent of effector differentiation," Immunity, vol. 25, no. 1, pp. 129-141, 2006.

[145] X. Cao, S. F. Cai, T. A. Fehniger et al., "Granzyme B and perforin are important for regulatory $\mathrm{T}$ cell-mediated suppression of tumor clearance," Immunity, vol. 27, no. 4, pp. 635-646, 2007.

[146] A. Boissonnas, A. Scholer-Dahirel, V. Simon-Blancal et al., "Foxp3+ T cells induce perforin-dependent dendritic cell death in tumor-draining lymph nodes," Immunity, vol. 32, no. 2, pp. 266-278, 2010.

[147] B. Huang, P. Y. Pan, Q. Li et al., "Gr-1+CD115+ immature myeloid suppressor cells mediate the development of tumorinduced $\mathrm{T}$ regulatory cells and T-cell anergy in tumorbearing host," Cancer Research, vol. 66, no. 2, pp. 1123-1131, 2006.

[148] P. Serafini, S. Mgebroff, K. Noonan, and I. Borrello, "Myeloid-derived suppressor cells promote cross-tolerance in B-cell lymphoma by expanding regulatory T cells," Cancer Research, vol. 68, no. 13, pp. 5439-5449, 2008.

[149] M. D. Sharma, B. Baban, P. Chandler et al., "Plasmacytoid dendritic cells from mouse tumor-draining lymph nodes directly activate mature Tregs via indoleamine 2,3dioxygenase," Journal of Clinical Investigation, vol. 117, no. 9, pp. 2570-2582, 2007.

[150] D. L. Barber, E. J. Wherry, D. Masopust et al., "Restoring function in exhausted CD8 $\mathrm{T}$ cells during chronic viral infection," Nature, vol. 439, no. 7077, pp. 682-687, 2006.

[151] M. Ahmadzadeh, L. A. Johnson, B. Heemskerk et al., "Tumor antigen-specific CD8 T cells infiltrating the tumor express high levels of PD-1 and are functionally impaired," Blood, vol. 114, no. 8, pp. 1537-1544, 2009.

[152] S. Mumprecht, C. Schürch, J. Schwaller, M. Solenthaler, and A. F. Ochsenbein, "Programmed death 1 signaling on chronic myeloid leukemia-specific T cells results in T-cell exhaustion and disease progression," Blood, vol. 114, no. 8, pp. 15281536, 2009.

[153] L. M. Francisco, V. H. Salinas, K. E. Brown et al., "PD$\mathrm{L} 1$ regulates the development, maintenance, and function of induced regulatory T cells," Journal of Experimental Medicine, vol. 206, no. 13, pp. 3015-3029, 2009.

[154] L. Wang, K. Pino-Lagos, V. C. De Vries, I. Guleria, M. H. Sayegh, and R. J. Noelle, "Programmed death 1 ligand signaling regulates the generation of adaptive Foxp3+CD4+ regulatory T cells," Proceedings of the National Academy of Sciences of the United States of America, vol. 105, no. 27, pp. 9331-9336, 2008.

[155] H. Dong, S. E. Strome, D. R. Salomao et al., "Tumorassociated B7-H1 promotes T-cell apoptosis: a potential mechanism of immune evasion," Nature Medicine, vol. 8, no. 9, pp. 793-800, 2002. 
[156] M. J. Butte, M. E. Keir, T. B. Phamduy, A. H. Sharpe, and G. J. Freeman, "Programmed death-1 ligand 1 interacts specifically with the B7-1 costimulatory molecule to inhibit T cell responses," Immunity, vol. 27, no. 1, pp. 111-122, 2007.

[157] J. J. Park, R. Omiya, Y. Matsumura et al., "B7-H1/CD80 interaction is required for the induction and maintenance of peripheral T-cell tolerance," Blood, vol. 116, no. 8, pp. 12911298, 2010.

[158] R. Yamamoto, M. Nishikori, T. Kitawaki et al., "PD-1 PD-1 ligand interaction contributes to immunosuppressive microenvironment of Hodgkin lymphoma," Blood, vol. 111, no. 6, pp. 3220-3224, 2008.

[159] Z. Z. Yang, A. J. Novak, M. J. Stenson, T. E. Witzig, and S. M. Ansell, "Intratumoral CD4+CD25+ regulatory T-cellmediated suppression of infiltrating CD4+ T cells in B-cell non-Hodgkin lymphoma," Blood, vol. 107, no. 9, pp. 36393646, 2006.

[160] H. Ghebeh, E. Barhoush, A. Tulbah, N. Elkum, T. AlTweigeri, and S. Dermime, "FOXP3+ Tregs and B7-H1+/PD$1+\mathrm{T}$ lymphocytes co-infiltrate the tumor tissues of highrisk breast cancer patients: implication for immunotherapy," BMC Cancer, vol. 8, article 57, 2008.

[161] J. F. M. Jacobs, A. J. Idema, K. F. Bol et al., "Regulatory T cells and the PD-L1/PD-1 pathway mediate immune suppression in malignant human brain tumors," Neuro-Oncology, vol. 11, no. 4, pp. 394-402, 2009.

[162] S. Wei, A. B. Shreiner, N. Takeshita, L. Chen, W. Zou, and A. E. Chang, "Tumor-induced immune suppression of in vivo effector T-cell priming is mediated by the B7-H1/PD-1 axis and transforming growth factor $\beta$," Cancer Research, vol. 68, no. 13, pp. 5432-5438, 2008.

[163] Q. Zhou, M. E. Munger, S. L. Highfill et al., "Program death1 signaling and regulatory $\mathrm{T}$ cells collaborate to resist the function of adoptively transferred cytotoxic $\mathrm{T}$ lymphocytes in advanced acute myeloid leukemia," Blood, vol. 116, no. 14, pp. 2484-2493, 2010.

[164] M. A. Cheever, "Twelve immunotherapy drugs that could cure cancers," Immunological Reviews, vol. 222, no. 1, pp. 357-368, 2008.

[165] E. M. Sotomayor, I. Borrello, E. Tubb et al., "Conversion of tumor-specific CD4+ T-cell tolerance to T-cell priming through in vivo ligation of cd40," Nature Medicine, vol. 5, no. 7, pp. 780-787, 1999.

[166] J. R. Brahmer, C. G. Drake, I. Wollner et al., "Phase I study of single-agent anti-programmed death-1 (MDX1106) in refractory solid tumors: safety, clinical activity, pharmacodynamics, and immunologic correlates," Journal of Clinical Oncology, vol. 28, no. 19, pp. 3167-3175, 2010.

[167] J. Rosenblatt, B. Vasir, L. Uhl et al., "Vaccination with dendritic cell/tumor fusion cells results in cellular and humoral antitumor immune responses in patients with multiple myeloma," Blood, vol. 117, no. 2, pp. 393-402, 2011.

[168] J. Yuan, S. Gnjatic, H. Li et al., "CTLA-4 blockade enhances polyfunctional NY-ESO-1 specific T cell responses in metastatic melanoma patients with clinical benefit," Proceedings of the National Academy of Sciences of the United States of America, vol. 105, no. 51, pp. 20410-20415, 2008.

[169] P. Attia, A. V. Maker, L. R. Haworth, L. Rogers-Freezer, and S. A. Rosenberg, "Inability of a fusion protein of IL2 and diphtheria toxin (Denileukin Diftitox, DAB389IL-2, ONTAK) to eliminate regulatory $\mathrm{T}$ lymphocytes in patients with melanoma," Journal of Immunotherapy, vol. 28, no. 6, pp. 582-592, 2005.
[170] J. Dannull, Z. Su, D. Rizzieri et al., "Enhancement of vaccine-mediated antitumor immunity in cancer patients after depletion of regulatory T cells," Journal of Clinical Investigation, vol. 115, no. 12, pp. 3623-3633, 2005.

[171] M. D. Sharma, D. Y. Hou, B. Baban et al., "Reprogrammed Foxp3+ regulatory $\mathrm{T}$ cells provide essential help to support cross-presentation and CD8+ T cell priming in naive mice," Immunity, vol. 33, no. 6, pp. 942-954, 2010. 


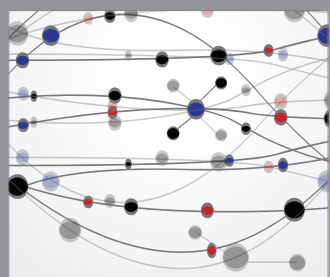

The Scientific World Journal
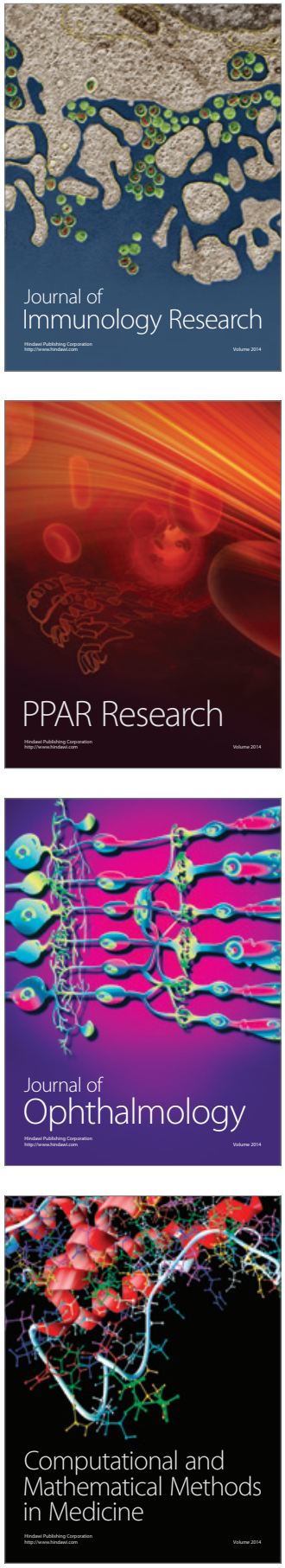

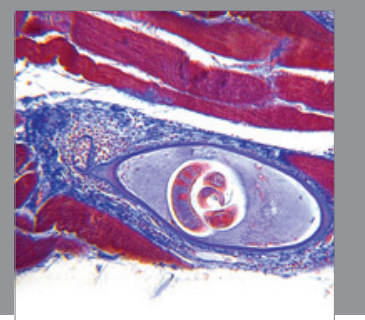

Gastroenterology

Research and Practice
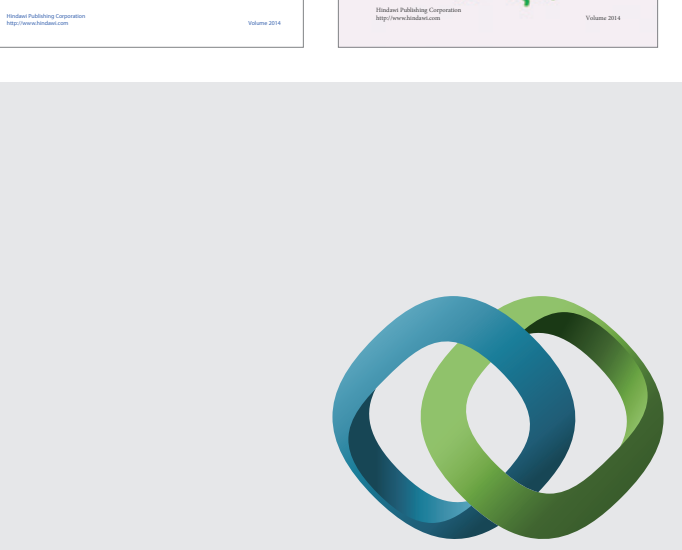

\section{Hindawi}

Submit your manuscripts at

http://www.hindawi.com
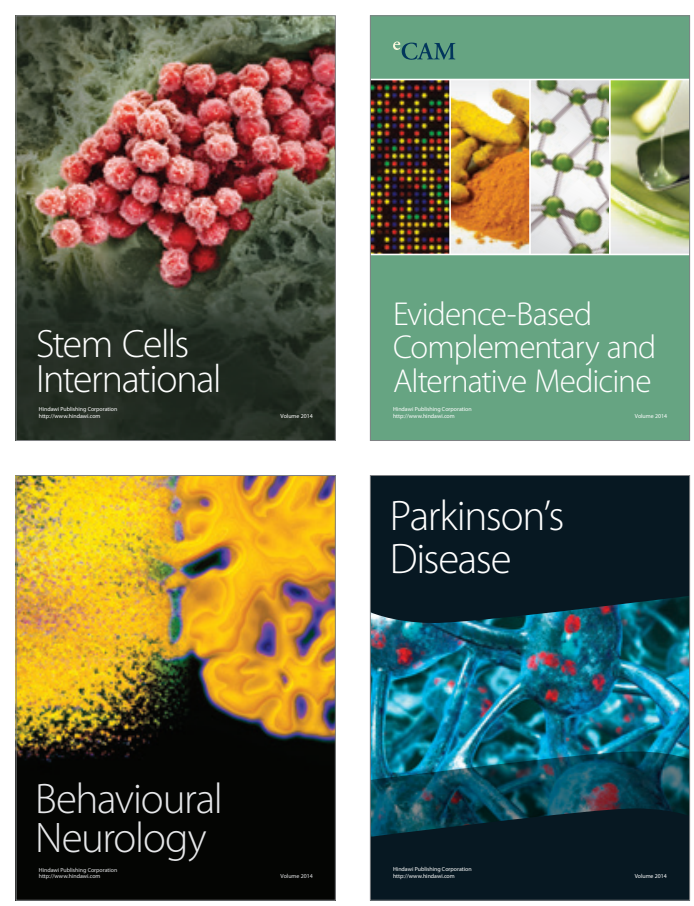

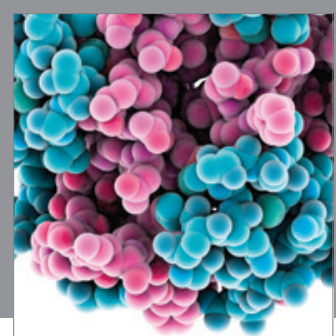

Journal of
Diabetes Research

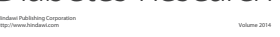

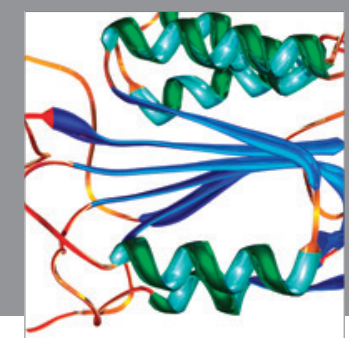

Disease Markers
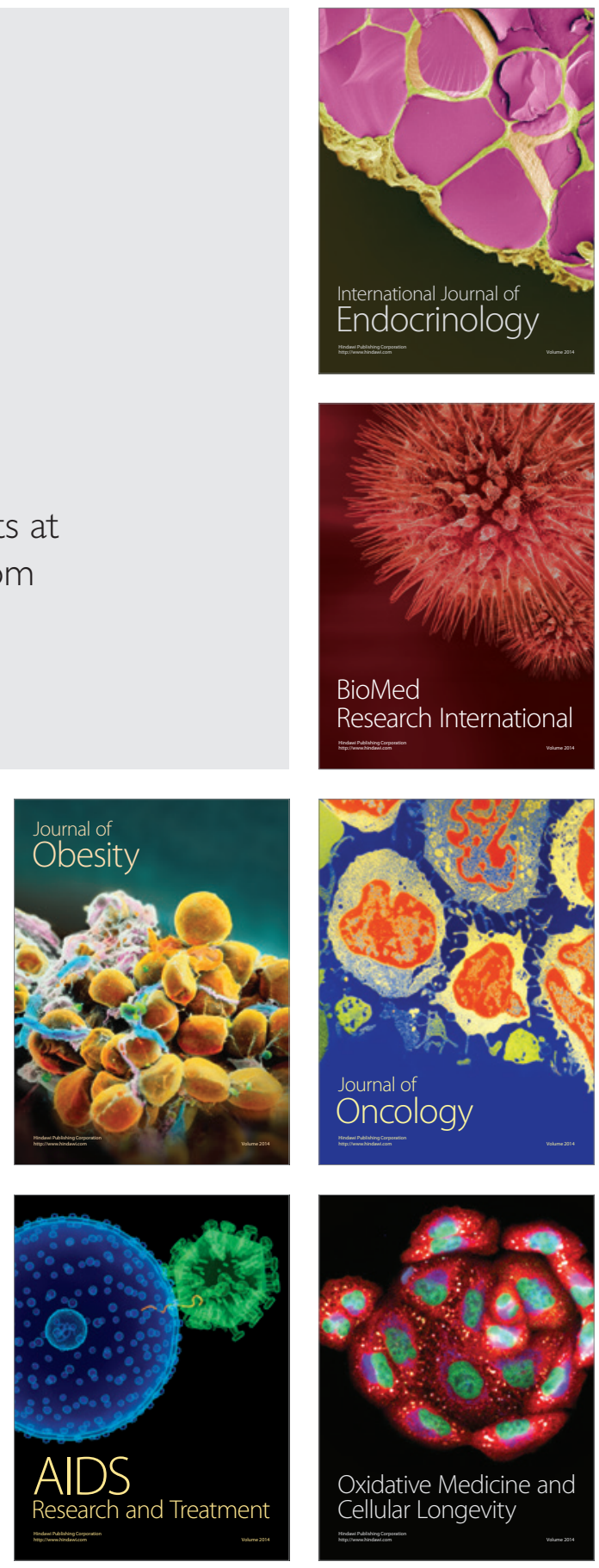